\title{
Effects of frond length on diverse gastropod assemblages in coralline turf
}

\author{
Brendan P. Kelaher \\ Centre for Research on Ecological Impacts of Coastal Cities, Marine Ecology Laboratories All, University of Sydney, \\ New South Wales 2006, Australia. Present address: Department of Ecology and Evolution, Life Sciences Building, \\ State University of New York, Stony Brook, NY 11974-5245, USA. E-mail: bkelaher@life.bio.sunysb.edu
}

\begin{abstract}
Habitat mimics were used to investigate the role of coralline algal frond length in determining spatial patterns in diverse gastropod assemblages on a rocky shore near Sydney, Australia. Frond length represents the vertical scale component of habitat structure, which is rarely experimentally manipulated. Length of fronds did not explain differences between gastropod assemblages at different tidal heights or among patches of turf separated by tens of metres in mid-shore areas. In contrast, changes in frond length caused large differences in the structure of gastropod assemblages in low-shore areas. Contrary to previous studies, the total abundance and diversity of gastropods was greater in turf with short fronds than with long fronds. Possible mechanisms for this negative relationship are discussed. Overall, the vertical scale component of habitat structure can have strong effects on associated faunal assemblages, but the magnitude of these effects depend heavily on local environmental conditions (e.g. different tidal heights).
\end{abstract}

\section{INTRODUCTION}

The physical structure of habitats strongly influences local species diversity and abundance in marine ecosystems (Heck \& Wetstone, 1977; Dean \& Connell, 1987a). Habitat structure modifies local environmental conditions and influences a variety of biological processes. For example, changes in habitat structure may affect levels of predation (Orth et al., 1984; Dean \& Connell, 1987b), the impact of disturbances (e.g. effects of wave action, Dommasnes, 1968), competitive interactions (Fletcher \& Underwood, 1987) or the physical harshness of the environment (e.g. relative humidity, Nixon et al., 1971). Furthermore, increasing habitat structure generally increases available surface area (see McGuinness \& Underwood, 1986 for review), which may create more micro-habitats or niches for associated fauna (Schoener, 1974).

Despite these important effects, the role of habitat structure in determining local community dynamics has generally received less attention than other factors (e.g. competition or predation) because of inconsistencies in how habitat structure has been defined (McCoy \& Bell, 1991). To solve this problem, McCoy \& Bell (1991) developed a conceptual model of habitat structure that is proving exceptionally useful for elucidating differences among the effects of its various characteristics (e.g. Downes et al., 1998). The model has three major components: (i) complexity, the absolute abundance of individual structural components per unit area (e.g. number of sea grass shoots per unit area); (ii) heterogeneity, the relative abundance of differently shaped structural components per unit area (e.g. different species of sea grass within a patch); and (iii) scale, the area used to measure heterogeneity or complexity. Although these definitions cover most aspects of habitat structure, they neglect changes in vertical size of structural components, which can occur without affecting either heterogeneity or complexity (e.g. the length of sea grass shoots). Changes in the vertical height of habitat structure affects the amount of available surface area. These changes may also affect the influences of habitat structure on a range of environmental (e.g. effects of waves, Dommasnes, 1968) and biotic (e.g. predation, Orth et al., 1984) factors. Few studies, however, have explicitly investigated the importance of vertical size of structural components in marine habitats.

Turf-forming articulated coralline algae are a major component of algal assemblages on many rocky shores (Stewart, 1982; Dye, 1993). The physical structure created by coralline turf generates habitat for diverse gastropod assemblages (Hicks, 1971), which can contain 100,000 individuals per $\mathrm{m}^{2}$ (Kelaher et al., 2001). The structure of these assemblages changes with tidal height, with gastropods generally being more diverse and abundant in lowshore areas (Kelaher et al., 2001). Within each height on the shore, there is also significant variability in gastropod assemblages among patches of turf separated by tens of metres (Kelaher et al., 2001).

Similar to gastropods, the length of coralline fronds is greater in low- than in mid-shore areas and varies among patches within each tidal height (Kelaher et al., 2001). The vertical scale component of coralline turf may, therefore, have a major influence on gastropod assemblages. To evaluate this, habitat mimics were used to test the hypothesis that frond length determines differences in gastropod assemblages between low- and mid-shore areas and between patches of turf separated by tens of metres within each height on the shore.

\section{MATERIALS AND METHODS \\ Experimental procedures}

The study was done at the Cape Banks Scientific Marine Research Area, on the northern headland of the entrance 
to Botany Bay, Sydney, Australia (see Underwood, 1975 for description). The rock platforms at this shore are relatively wave exposed and are often covered with large patches of coralline algal turf in low- and mid-shore areas. These turfs are dominated by Corallina officinalis Linnaeus, although many other algal species and a diverse epiphytic assemblage may be present at different times (Kelaher et al., 2001).

To evaluate the influence of coralline frond length on assemblages of gastropods, a field experiment was set up in May 1999 using patches of artificial turf with long (26 mm) or short $(13 \mathrm{~mm})$ fronds. These lengths of fronds fall within the natural range of coralline frond lengths (Kelaher et al., 2001). The artificial turf (manufactured by the Grass Alternative Pty Ltd, Sydney) was made of bundles of 16 polypropylene strips, separated from each other by $6 \mathrm{~mm}$ and attached in regular rows $(10 \mathrm{~mm}$ apart) to a latex back. Each polypropylene strip was $1.5 \mathrm{~mm}$ wide. Artificial turf is an excellent habitat mimic for coralline turf because it has similar mat-like structure, traps sediment and is quickly colonized by epiphytes and the frond length does not change in response to local environmental conditions. Furthermore, previous studies have shown that gastropod assemblages in these artificial turfs are not significantly different from those in natural coralline turf after four months (Kelaher, 2001).

Six sites $(2 \times 2 \mathrm{~m}$ areas of coralline turf) were haphazardly selected in both low- $(0.35-0.44 \mathrm{~m}$ above Indian Low Water Springs (ILWS), tidal datum for Sydney) and mid-shore (046-0.81 m above ILWS) areas. Each site was approximately 10-20 m from its nearest neighbour. At each height on the shore, three sites were randomly allocated to a treatment with turf with long fronds and three sites to a treatment of turf with short fronds. This randomization ensured that the frond length of surrounding coralline turf did not systematically influence colonization. In each site, four patches of artificial turf $(80 \mathrm{~mm}$ in diameter, $0.005 \mathrm{~m}^{2}$ ) of the particular treatment were attached to the rock platform. This size of patch was used because it provides reasonably precise estimates of the richness and abundance of gastropods (Kelaher, 2000). To attach each patch, a circular clearing of $80 \mathrm{~mm}$ in diameter was made in natural coralline turf. The artificial turf was glued to an aluminum sheet $(0.6 \mathrm{~mm}$ thick) for rigidity and attached to the cleared areas by three stainless steel screws. Clearings were carefully made to minimize the gap between the edge of the artificial turf and the surrounding coralline algae.

After six months, all patches were collected and preserved in 7\% formalin. In the laboratory, each replicate patch was washed thoroughly in a $500-\mu \mathrm{m}$ sieve and all remaining gastropods were identified to species and counted under $\times 16$ magnification. Six months was an appropriate amount of time to ensure densities of gastropods in artificial turf were similar to those in natural coralline turf (Kelaher, 2002). In total, 45 species of gastropods were found from 26 different families (see Kelaher, 2000 for complete species list). The assemblage was comprised of species that never grow larger than a few $\mathrm{mm}$ and juveniles of species of larger gastropods that are usually found in other habitats as adults. The size range of gastropods varied from $500 \mu \mathrm{m}$ to approximately $30 \mathrm{~mm}$.

\section{Statistical analysis}

Non-parametric multivariate analyses of variance (np-MANOVA) were used to test hypotheses about differences in gastropod assemblages (Anderson, 2001).

The np-MANOVAs were followed by a posteriori pairwise comparisons on appropriate terms in the model found to be significant at $P \leqslant 0.05$. Non-metric multidimensional

Table 1. (A) $n p-M A N O V A$ and $(B, C, D)$ ANOVAs of measures of gastropods assembalges $(\mathcal{N}=4)$.

\begin{tabular}{|c|c|c|c|c|c|c|c|}
\hline & \multirow[b]{2}{*}{$\mathrm{df}$} & \multicolumn{3}{|c|}{ (A) Gastropod assemblages } & \multicolumn{3}{|c|}{ (B) Species richness } \\
\hline & & MS & $p-F$ & $P$ & MS & $F$ & $P$ \\
\hline $\mathrm{He}$ & 1 & 21580.1 & 8.54 & 0.001 & 27.00 & 2.61 & 0.150 \\
\hline Le & 1 & 12123.4 & 4.80 & 0.001 & 44.08 & 4.26 & 0.073 \\
\hline $\mathrm{He} \times \mathrm{Le}$ & 1 & 5194.9 & 2.05 & 0.050 & 6.75 & 0.65 & 0.443 \\
\hline Site $(\mathrm{He} \times \mathrm{Le})$ & 8 & 2527.9 & 2.55 & 0.001 & 10.35 & 2.61 & 0.023 \\
\hline \multirow[t]{3}{*}{ Residual } & 36 & 991.1 & & & 3.97 & & \\
\hline & & \multicolumn{3}{|c|}{ (G) Evenness } & \multicolumn{3}{|c|}{ (D) Total abundance* } \\
\hline & df & MS & $F$ & $P$ & MS & $F$ & $P$ \\
\hline $\mathrm{He}$ & 1 & 0.006 & 0.19 & 0.676 & 6.61 & 13.99 & 0.006 \\
\hline Le & 1 & 0.003 & 0.09 & 0.770 & 4.60 & 9.74 & 0.014 \\
\hline $\mathrm{He} \times \mathrm{Le}$ & 1 & 0.017 & 0.58 & 0.467 & 0.90 & 1.91 & 0.204 \\
\hline Site $(\mathrm{He} \times \mathrm{Le})$ & 8 & 0.029 & 2.85 & 0.014 & 0.47 & 1.38 & 0.236 \\
\hline Residual & 36 & 0.010 & & & 0.34 & & \\
\hline
\end{tabular}

He, fixed comparison between low- and mid-shore area; Le, fixed comparison between turf with short and long fronds; Site, comparison of sites nested in the interaction term. $p-F$, pseudo- $F$ ratios generated by permutation tests; *, data transformed by $\operatorname{Ln}(x+1)$ function. 

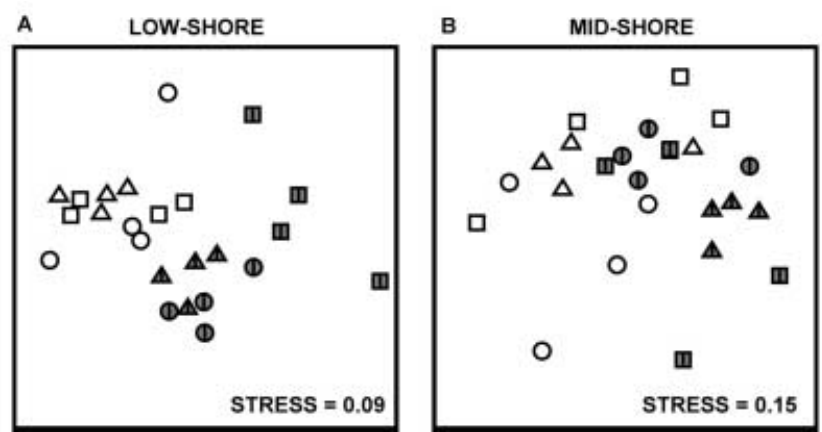

Figure 1. Two dimensional nMDS ordination $(\mathrm{N}=4)$ comparing gastropod assemblages in turf with short fronds (unfilled symbols) and with long fronds (grey symbols) in (A) low-shore and (B) mid-shore areas. Each different symbol outline represents a different site.

scaling (nMDS, Field et al., 1982) was used to produce two-dimensional ordination plots to show relationships among assemblages of gastropods. All multivariate analyses were done using Bray-Curtis similarity coefficients (Bray \& Curtis, 1957).

Analyses of variance (ANOVA) were used to test hypotheses about the total number of species, total abundance and the evenness of gastropod assemblages $\left(\mathcal{f}^{\prime}\right.$, Pielou, 1975). The ANOVAs were preceded with Cochran's test for homogeneity of variances. Where necessary, data were transformed using a $\operatorname{Ln}(x+1)$ function, after which no Cochran's test was significant.

\section{RESULTS}

The gastropod assemblages in turf with short fronds were significantly different from those in turf with long fronds in low-shore (post-hoc tests, $P<0.01$ ), but not midshore areas (post-hoc tests, $P>0.05$, see interaction in Table 1A). These results are clearly illustrated in the nMDS plots (Figure 1). For low-shore areas, there are two separate groups of points representing large differences in gastropod assemblages in treatments with long and short fronds (Figure 1A). In mid-shore areas, however, the structure of gastropod assemblages in these treatments substantially overlapped (Figure 1B).

There were differences between gastropod assemblages in low- and in mid-shore areas, regardless of frond length (post-hoc tests, $P<0.01$, Figure 1). These differences combined with the inconsistent effects of frond length on gastropods at different tidal heights, indicate that the vertical structure of coralline turf cannot explain much of the variation between gastropods assemblages in low- and mid-shore areas.

The ten gastropods with the largest contributions to dissimilarity accounted for $96 \%$ and $87 \%$ of the total Bray-Curtis Dissimilarity in low- and mid-shore areas, respectively. The identity of eight of the top ten contributing gastropod species was similar in low- and midshore areas, but their rankings differed (Table 2). These variations in ranking contributed substantially to the multivariate interaction between the effects of tidal height and frond length $(\mathrm{He} \times$ Le interaction in Table 1$)$.

The small gastropod, Eatoniella atropurpurea (Fruenfeld, 1867), made the largest contribution to differences between gastropod assemblages in turf of different frond lengths and tended to be more abundant in turf with short fronds (Table 2). There was little consistency in the contributions of other individual species. For example, the percentage contribution of the small limpet, Patellioda mufria (Hedley, 1915), was almost double in mid-shore areas, compared to low-shore areas. In contrast, the per cent contribution of the small snail, Amphithalamus incidata (Fruenfeld, 1867), was almost five times greater in lowthan in mid-shore areas. It should be noted, however, that the absolute contributions of individual species to total dissimilarity were much greater in low- than midshore areas because the total dissimilarity was substantially higher in low-shore areas.

Neither the number of species of gastropods nor the evenness of gastropod assemblages significantly differed between low- and mid-shore areas or between turfs with short and long fronds (Table 1B,C; Figure 2). There was, however, a trend toward greater species richness of gastropods in turf with shorter fronds $(P<0.073)$, especially in low-shore areas. This trend would have certainly contributed to the strong multivariate effects in low-shore

Table 2. Total Bray-Curtis dissimilarities and percentage contributions of individual species for comparisons of gastropod assemblages in turf with long and short fronds $(A)$ in low-shore areas and $(B)$ in mid-shore areas. The ten species included had the largest contributions to dissimilarity at each tidal height and accounted for $96 \%$ and $87 \%$ of the total dissimilarity among treatments in low- and mid-shore areas, respectively.

(A) Low-shore

(B) Mid-shore

\begin{tabular}{lll}
\hline Total dissimilarity & 67.03 & Total dissimilarity \\
Eatoniella atropurpurea & 32.65 & Eatoniella atropurpurea \\
Amphithalamus incidata & 18.47 & Patellioda mufria \\
Patellioda mufria & 14.29 & Montfortula rugosa \\
Eatonina rubrilabiata & 12.70 & Amphithalamus incidata \\
Rissoella micra & 6.00 & 8.06 \\
Rissoella confusa & 4.20 & Notoacmea flammea \\
Montfortula rugosa & 3.35 & Austrococlea poracata \\
Sinezona atkinsoni & 2.80 & Rissoella micra \\
Aplysia sp. & 0.80 & Scrobs luteofuscus \\
Turbo undulatus & 0.57 & Eatonina rubrilabiata \\
\end{tabular}



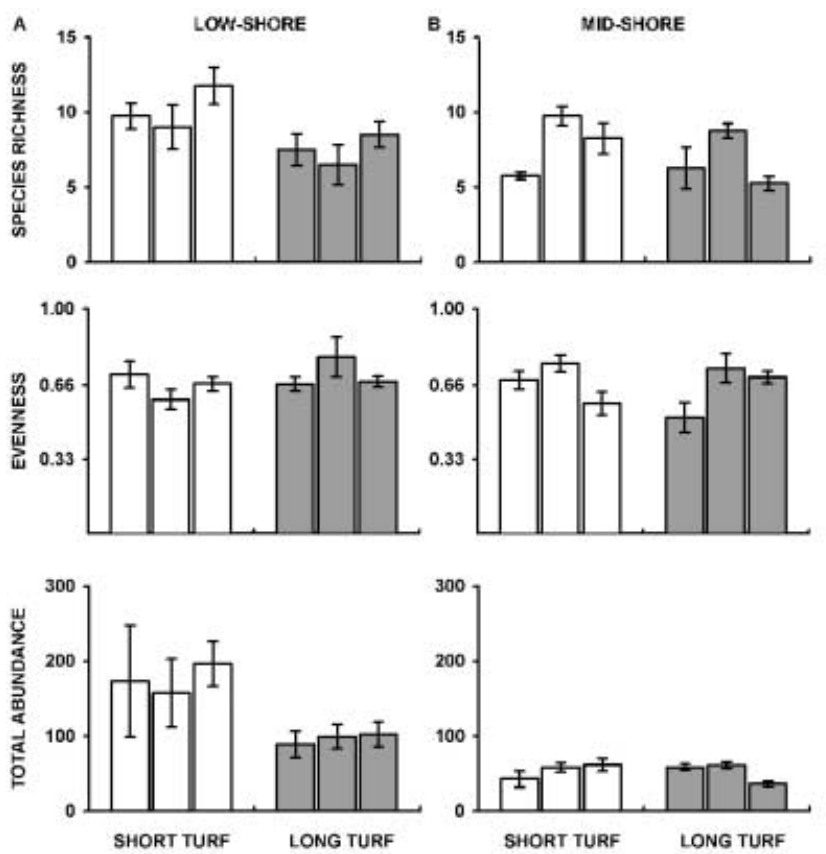

Figure 2. Comparisons of mean $(\mathrm{SE}, \mathrm{N}=4)$ univariate measures of gastropod assemblages in turf with short fronds (unfilled bars) and with long fronds (grey bars) in (A) low- and (B) mid-shore areas. Each bar represents a different site.

areas. There was also significant site-to-site variation in the number of species of gastropods and evenness of gastropod assemblages.

The total abundance of gastropods was significantly greater in turf with shorter fronds than in turf with longer fronds (Table 1D; Figure 2). These differences were much more pronounced in low-shore areas, where there were significantly more gastropods (Table 1D; Figure 2).

\section{DISCUSSION}

Few studies have experimentally investigated the role of habitat structure in determining differences between faunal assemblages at different tidal heights (Lohrer et al., 2000). Although coralline fronds are longer and gastropods are more abundant in low- than mid-shore areas, the length of fronds explained little variation between gastropod assemblages at low- and mid-shore levels. Similar conclusions have been made about the structural complexity of coralline fronds (Kelaher, 2000). Habitat structure in general, therefore, has little influence on gastropod assemblages in coralline turf at different tidal heights. Consequently, other biological processes (e.g. recruitment, predation, competition), physical disturbances or environmental factors must be responsible for these differences (see Underwood, 1994 for review).

In contrast, the length of coralline fronds had major effects on gastropod assemblages in low-shore areas and therefore contributed significantly to spatial variation of gastropods at this tidal height. In mid-shore areas, there was some evidence to suggest that the total abundance of gastropods was affected by frond length, but the effect size was substantially smaller than in low-shore areas. The vertical size of habitat structure on gastropods, therefore, strongly interacted with local conditions at different tidal heights. This conclusion was further supported by the significant multivariate interaction between tidal height and frond length, which was mostly caused by proportionally greater changes in abundances of gastropods among treatments in low-shore areas.

Habitat surface area is often a good predictor of species richness and abundance (McGuinness \& Underwood, 1986). Generally as the surface area of a habitat increases, the diversity and abundance of associated fauna also increases (Heck \& Wetstone, 1977; Dean \& Connell, 1987a). In a few cases, however, no relationship between these variables has been reported (Russo, 1990). In contrast, the relationship between frond length and the abundance and possibly species richness of gastropods in this study was strongly negative in low-shore areas. These results were, however, not entirely unexpected because a negative correlation is known to exist between the diversity of gastropods and frond length in low-shore areas on similar rocky shores spanning $120 \mathrm{~km}$ of coast (Kelaher et al., 2001). The combination of the experimental and correlative results demonstrates conclusively that surface area of fronds may not always be a good predictor of local gastropod diversity and abundance in algal turf.

There are a number of factors that may have contributed to these negative effects. One possible mechanism is the relationship between sediment deposition and frond length. Kelaher (2000) reported negative correlations between frond length and accumulated sediment in lowshore areas, but found no such relationship in mid-shore areas. The amount of sediment in algal turf has been positively associated with greater richness and abundances of gastropods (Wigham, 1975; Kelaher et al., 2001) and with larger amounts of detritus (Hicks, 1980). Sediment trapped by algal turf provides a habitat for many species of gastropods (Olabarria \& Chapman, 2001) and detritus is an important source of food. In support of this model, several gastropod species that had large contributions to the BrayCurtis dissimilarities between treatments, Amphithalamus incidata and Eatonina rubrilabiata, have been strongly associated with the amount of sediment in coralline turf (Kelaher, 2000; Olabarria \& Chapman, 2001).

An alternative explanation is the dislodgement of grazing gastropods caused by the rapid movement of long coralline fronds propelled by strong wave action. The whiplash of algae in surge has been shown to negatively affect intertidal organisms (Lewis, 1964; Jenkins, 1999). Most of this research has focused on the effects of frond scouring, but it is likely that algal whiplash also removes substantial numbers of organisms foraging on the fronds. The movement of coralline fronds is generally greater in low- than in mid-shore areas because coralline fronds are longer (up to $5 \mathrm{~cm}$ ), more loosely packed and wave action is greater. Evidence for a whiplash effect comes from the most abundant gastropod, Eatoniella atropurpurea, which was also negatively associated with frond length. This species is usually found foraging on the fronds, rather than in sediment at the base of the turf. It is therefore likely to be affected by frond movement, rather than variation in accumulated sediment. Clearly, careful experimental manipulations are required to determine the exact mechanisms responsible for the negative effects of frond length on gastropod assemblages. 
Like other components of habitat structure (e.g. heterogeneity and complexity), changes in the vertical height of habitat structure can have strong influences on local assemblages. This characteristic should, therefore, be added to three essential components of habitat structure (heterogeneity, complexity and scale) in McCoy \& Bell's (1991) general model. The magnitude of effects of frond length on gastropod assemblages in coralline turf were, however, inconsistent and strongly modulated by local environmental conditions (e.g. tidal height). From these results, therefore, it is difficult to make accurate predictions about the effects of the vertical size of habitat structure in other marine habitats. Consequently, further experimental tests of this component are needed in a variety of habitats, if we are to fully understand the important role of habitat structure in marine systems.

This study was part of a PhD supported by an Australian PostGraduate Award and by funds from the Australian Research Council through the Centre for Research on Ecological Impacts of Coastal Cities. I would like to thank my advisors Professor A.J. Underwood and Dr M.G. Chapman for their help in various parts of this study. I am also grateful to I.W. Ashton, L.A. Hyatt, B.J. Allen for comments on earlier drafts of this manuscript.

\section{REFERENCES}

Anderson, M.J., 2001. A new method for non-parametric multivariate analysis of variance in ecology. Austral Ecology, 26, 32-46.

Bray, J.R. \& Curtis, J.T., 1957. An ordination of the upland forest communities of Southern Wisconsin. Ecological Monographs, 27, 325-349.

Dean, R.L. \& Connell, J.H., 1987a. Marine invertebrates in algal succession. II. Tests of hypotheses to explain diversity with succession. Fournal of Experimental Marine Biology and Ecology, 109, 217-247.

Dean, R.L. \& Connell, J.H., 1987b. Marine invertebrates in algal succession. III. Mechanisms linking habitat complexity with diversity. Fournal of Experimental Marine Biology and Ecology, 107, 249-273.

Dommasnes, A., 1968. Variations in the meiofauna of Corallina officinalis L. with wave exposure. Sarsia, 34, 117-124.

Downes, B.J., Lake, P.S., Schreiber, E.S.G. \& Glaister, A., 1998. Habitat structure and regulation of local species diversity in a stony, upland stream. Ecological Monographs, 68, 237-257.

Dye, A.H., 1993. Recolonization of intertidal macroalgae in relation to gap size and molluscan herbivory on a rocky shore on the east coast of Southern Africa. Marine Ecology Progress Series, 95, 263-271.

Edgar, G.J., Shaw, C., Watson, G.F. \& Hammond, L.S., 1994. Comparisons of species richness, size-structure and production of benthos in vegetated and unvegetated habitats in WesternPort, Victoria. Fournal of Experimental Marine Biology and Ecology, 176, 201-226.

Field, J.G., Clarke, K.R. \& Warwick, R.M., 1982. A practical strategy for analysing multispecies distribution patterns. Marine Ecology Progress Series, 8, 37-52.

Fletcher, W.J. \& Underwood, A.J., 1987. Interspecific competition among subtidal limpets - effect of substratum heterogeneity. Ecology, 68, 387-400.

Heck, K.L. \& Wetstone, G.S., 1977. Habitat complexity and invertebrate species richness and abundance in tropical seagrass meadows. Fournal of Biogeography, 4, 135-142.
Hicks, G.R.F., 1971. Check list and ecological notes on the fauna associated with some littoral corallinacean algae. Bulletin of Natural Sciences, 2, 47-58.

Hicks, G.R.F., 1980. Structure of phytal harpacticoid copepod assemblages and the influence of habitat complexity and turbidity. Fournal of Experimental Marine Biology and Ecology, 44, 157-192.

Jenkins, S.R., Norton, T.A. \& Hawkins, S.J., 1999. Settlement and post-settlement interactions between Semibalanus balanoides (L.) (Crustacea: Cirripedia) and three species of fucoid canopy algae. Fournal of Experimental Marine Biology and Ecology, 236, 49-67.

Kelaher, B., 2000. Biodiversity of macrofaunal assemblages in coralline algal turf. $\mathrm{PhD}$ thesis, University of Sydney, Sydney, Australia.

Kelaher, B., 2002. Influence of physical characteristics of coralline turf on associated macrofaunal assemblages. Marine Ecology Progress Series, 232, 141-148.

Kelaher, B., Chapman, M.G. \& Underwood, A.J., 2001. Spatial patterns of diverse macrofaunal assemblages in coralline turf and their association with environmental variables. Fournal of the Marine Biological Association of the United Kingdom, 81, 1-14.

Lewis, J.R., 1964. The ecology of rocky shores. London: English Unversity Press.

Lohrer, A.M., Fukui, Y., Wada, K. \& Whitlatch, R.B., 2000. Structural complexity and vertical zonation of intertidal crabs, with focus on habitat requirements of the invasive Asian shore crab, Hemigrapsus sanguineus (de Haan). Fournal of Experimental Marine Biology and Ecology, 244, 203-217.

McCoy, E.D. \& Bell, S.S., 1991. Habitat structure: the evolution and diversification of a complex topic. In Habitat structure: the physical arrangement of objects in space (ed. S.S. Bell et al.), pp. 1-27. London: Chapman \& Hall.

McGuinness, K.A. \& Underwood, A.J., 1986. Habitat structure and the nature of communities on intertidal boulders. Fournal of Experimental Marine Biology and Ecology, 104, 97-123.

Nixon, S.W., Oviatt, G.A., Rodgers, G. \& Taylor, R.K., 1971. Mass and metabolism of a mussel bed. Oecologia, 8, 21-30.

Olabarria, C. \& Chapman, M.G., 2001. Habitat-associated variability in survival and growth of three species of microgastropods. Fournal of the Marine Biological Association of the United Kingdom, 81, 961-966.

Orth, R.J., Heck, K.L. \& Montfrans, J. van, 1984. Faunal communities in seagrass beds: a review of the influence of plant structure and predator characteristics on predator prey relationships. Estuaries, 7, 339-350.

Pielou, E.C., 1975. Ecological diversity. New York: Wiley.

Russo, A.R., 1990. The role of seaweed complexity in structuring Hawaiian epiphytal amphipod communities. Hydrobiologia, 194, 1-12.

Schoener, T.W., 1974. Resource partitioning in ecological communities. Science, New York, 185, 27-39.

Stewart, J.G., 1982. Anchor species and epiphytes in intertidal algal turf. Pacific Science, 36, 45-59.

Underwood, A.J., 1975. Comparative studies on the biology of Nerita atramentosa Reeve, Bembicium nanum (Lamarck) and Cellana tramoserica (Sowerby) (Gastropoda: Prosobranchia) in S.E. Australia. Fournal of Experimental Marine Biology and Ecology, 19, 153-172.

Underwood, A.J., 1994. Rocky intertidal shores. In Marine biology (ed. L.S. Hammond and R. Synnot), pp. 273-296. Melbourne: Longman-Cheshire.

Wigham, G.D., 1975. The biology and ecology of Rissoa parva (Da Costa) [Gastropoda: Prosobranchia]. Fournal of the Marine Biological Association of the United Kingdom, 55, 45-67.

Submitted 14 June 2002. Accepted 14 October 2002. 